DALALBA, Jennifer Leal Furtado Barreto; SOUILLJEE, Liege Giaretta; NISTLER, Regiane. A jurisdição no Estado Democrático de direito: uma breve análise do comportamento Ativista Judicial. Revista Eletrônica Direito e Política, Programa de Pós-Graduação Stricto Sensu em Ciência Jurídica da UNIVALI, Itajaí, v.13, n.1, $1^{\circ}$ quadrimestre de 2018. Disponível em: www.univali.br/direitoepolitica - ISSN 1980-7791

\title{
A JURISDIÇÃO NO ESTADO DEMOCRÁTICO DE DIREITO: UMA BREVE ANÁLISE DO COMPORTAMENTO ATIVISTA JUDICIAL
}

THE JURISDICTION IN THE DEMOCRATIC STATE OF LAW: A BRIEF ANALYSIS OF JUDICIAL ACTIVIST BEHAVIOR

Jennifer Leal Furtado Barreto Dalalba ${ }^{1}$ Liege Giaretta Souilljee ${ }^{2}$

Regiane Nistler ${ }^{3}$

SÚMARIO: Introdução; 1. Evolução do estado e jurisdição; 2. Ativismo judicial e o enfraquecimento da democracia; Considerações Finais; Referência das fontes citadas.

\section{RESUMO}

O presente artigo tem como objetivo realizar breve análise acerca do ativismo judicial, demonstrando especialmente a sua íntima ligação com os anseios sociais, evidenciados principalmente pelo modelo social de Estado. A pesquisa é dividida em duas seções, sendo que na primeira são analisados alguns pressupostos teóricos básicos acerca do Estado, como conceito, características, especialmente a jurisdição, e as formas estatais. Em ato contínuo e ao arremate, o instituto do ativismo judicial é estudado a partir da sua diferenciação da judicialização da política, seu conceito, assim como o curso que tem tomado. A metodologia utilizada é a pesquisa normativa (Constituição Federal de 1988, leis, etc.) e doutrinária.

Palavras-chave: Ativismo Judicial; Estado; Jurisdição

1 Mestre em Direito, Democracia e Sustentabilidade pela Faculdade Meridional (IMED), campus de Passo Fundo, RS. Professora do curso de Direito da Faculdade Anhanguera. E-mail: jennifer.barreto@aedu.com

2 Mestre em Direito, Democracia e Sustentabilidade na Faculdade Meridional - IMED, Passo Fundo - RS. Advogada e Professora do Curso de Direito da Ulbra, campus de Carazinho. Email: liegegs@yahoo.com

${ }^{3}$ Doutoranda em Direito pela Universidade Estácio de Sá (UNESA), campus do Rio de Janeiro, RJ. Mestre em Direito, Democracia e Sustentabilidade pela Faculdade Meridional (IMED), campus de Passo Fundo, RS. Especialista em Direito e Processo do Trabalho e Direito Previdenciário pelo Centro Universitário para o Desenvolvimento do Alto Vale do Itajaí Unidavi. Professora dos cursos de Direito, Administração e Engenharia Civil da Unidavi. Advogada (OAB/SC). E-mail: regianenistler@outlook.com 
DALALBA, Jennifer Leal Furtado Barreto; SOUILLJEE, Liege Giaretta; NISTLER, Regiane. A jurisdição no Estado Democrático de direito: uma breve análise do comportamento Ativista Judicial. Revista Eletrônica Direito e Política, Programa de Pós-Graduação Stricto Sensu em Ciência Jurídica da UNIVALI, Itajaí, v.13, n.1, $1^{\circ}$ quadrimestre de 2018. Disponível em: www.univali.br/direitoepolitica - ISSN 1980-7791

\section{ABSTRACT}

This article aims to carry out a brief analysis of judicial activism, especially showing its close connection with social desires, evidenced mainly by the social model of the State. The research is divided into two sections, the first of which analyzes some basic theoretical assumptions about the state, such as concept, characteristics, especially jurisdiction, and state forms. In continuation and at the end, the institute of judicial activism is studied from its differentiation of the judicialization of politics, its concept, as well as the course it has taken. The methodology used is normative research (Federal Constitution of 1988, laws, etc.) and doctrinal.

Keywords: Judicial Activism; State; Jurisdiction

\section{INTRODUÇÃO}

Os anseios da sociedade mudam em alta velocidade, o que é cristalino e evidenciado principalmente pelas formas estatais que são alteradas com o passar das décadas, quando seu nome e definição não mais correspondem às necessidades e ao próprio comportamento do seu povo.

Ocorre que o direito não passa ileso disso, pelo contrário, ele participa dessa mudança. A história demonstra esse fato a partir do modelo absolutista de Estado, por exemplo, que evidencia o poder e a soberania na coroa, no ouro, e quando todas as regras eram divinas, pois emanavam de Deus.

Em seguida o Estado liberal que pela primeira vez traz a soberania no povo, tem como traço marcante a separação de poderes, tão importante para a organização do Estado, e nas relações jurídicas estabelecidas, assim como na própria atuação da jurisdição, evidencia a nítida elevação do direito privado em detrimento do direito público, mas em razão da busca incessante dos indivíduos por lucro e os reclames por prestações sociais do Estado, esse modelo foi à bancarrota.

Adiante, o modelo social, que embasa as típicas Constituições democráticas, com inúmeros e qualificados direitos fundamentais e sociais, promete muitas vezes mais do que pode cumprir e apresenta um problema, tanto de estrutura, com as limitações inerentes, especialmente de recursos, como de função, ao gerir com pouca competência as poucas políticas públicas que cria. 
DALALBA, Jennifer Leal Furtado Barreto; SOUILLJEE, Liege Giaretta; NISTLER, Regiane. A jurisdição no Estado Democrático de direito: uma breve análise do comportamento Ativista Judicial. Revista Eletrônica Direito e Política, Programa de Pós-Graduação Stricto Sensu em Ciência Jurídica da UNIVALI, Itajaí, v.13, n.1, $1^{0}$ quadrimestre de 2018. Disponível em: www.univali.br/direitoepolitica - ISSN 1980-7791

Nesse sentido, as prestações sociais não concretizadas nos dias hoje, em gigante proporção, são judicializadas, ou seja, uma aparente inversão de poderes e consequentemente de competência, pois o judiciário precisa atender ao que os outros poderes não conseguiram.

Por isso, este estudo se debruça a estudar o instituto do ativismo judicial, que é intimamente ligado às mudanças da sociedade acima descritas, e com a judicialização da política, embora com esta última não se confunda, e é definido como o excesso do julgador ao tratar das demandas dessa natureza, nitidamente constitucionais, sendo um instituto com seus prós e contras, tanto para sociedade, como para o direito, e por isso, precisa ser analisado, conforme será feito, ainda que brevemente, a seguir.

\section{EVOLUÇÃO DO ESTADO E JURISDIÇÃO}

Nos ensinamentos de Romano Santi a definição de Estado mais ampla e sucinta que se pode criar é a de que Estado é toda ordenação jurídica territorial e que seja soberana, portanto, originária. A expressão 'ordenação jurídica', quando for conveniente ressaltar mais claramente certos aspectos do conceito, pode ser substituído por outros, substancialmente equivalentes, como 'ente', 'comunidade' ou ainda 'instituição'4.

Portanto, o Estado se trata de uma instituição organizada política, social e juridicamente, que se encontra em um território delimitado e, na maioria dos casos, sua lei maior é uma Constituição escrita. É administrado por um governo soberano reconhecido no plano nacional e internacional, sendo responsável pela organização e pelo controle social, pois ostenta o monopólio legítimo do uso da força e da coerção ${ }^{5}$.

A condição instrumental do Estado deve ser consequência de dupla causa: (1) ele nasce do povo; e (2) deve existir para atender as demandas que,

4 SANTI, Romano. Princípios de direito constitucional geral. São Paulo: ed. Revista dos Tribunais, 1977 , p. 59-60.

5 CICCO, Cláudio de; GONZAGA, Álvaro de Azevedo. Teoria Geral do Estado e ciência política. São Paulo: Editora Revista dos Tribunais, 2008. p. 43. 
DALALBA, Jennifer Leal Furtado Barreto; SOUILLJEE, Liege Giaretta; NISTLER, Regiane. A jurisdição no Estado Democrático de direito: uma breve análise do comportamento Ativista Judicial. Revista Eletrônica Direito e Política, Programa de Pós-Graduação Stricto Sensu em Ciência Jurídica da UNIVALI, Itajaí, v.13, n.1, $1^{\circ}$ quadrimestre de 2018. Disponível em: www.univali.br/direitoepolitica - ISSN 1980-7791

permanente ou conjunturalmente, a Sociedade necessita que sejam atendidas. O desconhecimento ou a incompetência demonstrada à efetivação desta dupla motivação é motivo para um "leviatã", muitas vezes, se prestar a oprimir os indivíduos socioeconomicamente mais frágeis em benefício de indivíduos privilegiados. Se a condição instrumental do Estado nasce do fato dele ser criação da Sociedade, ela se consolidará somente ao servir os anseios sociais e será justificada por uma conformação jurídica, dinâmica e conveniente na sua origem, e coerente com sua utilidade para a nação. ${ }^{6}$

Um marco histórico que merece atenção quando o estudo é a figura do Estado é a Paz de Westphalia, ou melhor dizendo, os Tratados da Paz de Westphalia, que marcam o conceito de estado-nação, especialmente pelas características da soberania, da territorialidade, do elemento humano e da própria jurisdição.

Os Tratados de Westphalia tiveram o caráter de documentação da existência de um novo tipo de Estado, com a característica básica de unidade territorial dotada de um poder soberano. Era já o Estado moderno, cujas marcas fundamentais, desenvolvidas espontaneamente, foram-se tornando mais nítidas com o passar do tempo e à medida que, claramente apontadas pelos teóricos, tiveram sua definição e preservação convertidas em objetivos do próprio Estado7.

Acerca das características do Estado, mais precisamente do espaço territorial, ensina Heller que não resta dúvida de que o Estado tem a sua lei própria e não se constitui unicamente da comunidade do espaço geográfico; mas a comunidade de espaço é condição essencial da unidade estatal. Uma zona geográfica fechada permite e estimula em alto grau a criação de uma

\footnotetext{
6 PASOLD, Cesar Luiz. Função Social do Estado Contemporâneo. Santa Catarina: Ladesc, 1984 , p. 46.

7 DALLARI, Dalmo de Abreu. Elementos de Teoria Geral do Estado. São Paulo: Saraiva, 2015. p. 59-60.
} 
DALALBA, Jennifer Leal Furtado Barreto; SOUILLJEE, Liege Giaretta; NISTLER, Regiane. A jurisdição no Estado Democrático de direito: uma breve análise do comportamento Ativista Judicial. Revista Eletrônica Direito e Política, Programa de Pós-Graduação Stricto Sensu em Ciência Jurídica da UNIVALI, Itajaí, v.13, n.1, $1^{0}$ quadrimestre de 2018. Disponível em: www.univali.br/direitoepolitica - ISSN 1980-7791

entidade sócio-política também fechada; a vizinhança atuará unindo para dentro e diferenciado para fora ${ }^{8}$.

No que tange ao elemento humano como uma referência de identificação do Estado, convém destacar as lições de Miranda, para quem o Estado consiste, especialmente, num grupo de pessoas, de homens, que ostentam o direito da liberdade. Constituem-no aqueles homens e aquelas mulheres que o seu Direito reveste da qualidade de cidadãos ou súditos e que permanecem unidos na obediência às mesmas regras, ou seja, às leis estatais ${ }^{9}$.

Assim, feitas as considerações acerca dos elementos do Estado, necessário analisar, considerando o objeto deste estudo, ainda que brevemente, as formas estatais, que evidenciam os outros elementos identificadores do Estado: a soberania e a jurisdição.

Na doutrina de Thomas Hobbes o Estado Absoluto, primeira versão do Estado Moderno, tinha como característica a designação de um homem ou uma assembleia de homens para representá-los, considerando e reconhecendo cada um como autor de todos os atos que aquele que representa sua pessoa praticasse, em tudo o que se refere à paz e segurança comuns, submetendo, assim, suas vontades à vontade do representante, e seus julgamentos a seu julgamento. Em razão da autoridade que cada indivíduo dá ao Estado, nesse modelo de Estado, que usa todo o poder de força, pelo termo que inspira é capaz de conformar todas as vontades, a fim de efetivar a paz em seu próprio país, e promover a ajuda mútua em face dos inimigos estrangeiros ${ }^{10}$.

Adiante, o denominado Estado liberal, que em como signo distintivo a separação de poderes e a preferência pelo direito privado em detrimento do

8 HELLER. Teoria do Estado. Tradução de Lycurgo Gomes da Motta. São Paulo: Mestre Jou, 1968. Título original: Staatslehre. p. 179. 71.

9 MIRANDA, Jorge. Teoria do Estado e da Constituição. Rio de Janeiro: Forense, 2011. p.

10 HOBBES, Thomas. Leviatã, ou a matéria, forma e poder de um estado eclesiástico e civil. Tradução de Rosina D’Angina. São Paulo: Ícone, 2000. Título original: Leviathan, or Matter, Form and Power of a Commenweath Ecclesiastical and Civil. p. 16. 
DALALBA, Jennifer Leal Furtado Barreto; SOUILLJEE, Liege Giaretta; NISTLER, Regiane. A jurisdição no Estado Democrático de direito: uma breve análise do comportamento Ativista Judicial. Revista Eletrônica Direito e Política, Programa de Pós-Graduação Stricto Sensu em Ciência Jurídica da UNIVALI, Itajaí, v.13, n.1, $1^{0}$ quadrimestre de 2018. Disponível em: www.univali.br/direitoepolitica - ISSN 1980-7791

direito público, e exatamente por ser um regime popular, em que a vontade do povo ditava a lei, absorveu o indivíduo e o próprio povo. Porque ambos, perante os novos problemas e as novas necessidades que iam aparecendo, incapazes de resolver aqueles e de suprir a estas, assim como de compreender uns e outras, imploravam e exigiam do Estado a solução e o remédio para todas as suas dificuldades e males. ${ }^{11}$

Dessa forma, o Estado tentou se agigantar exatamente para atender os pedidos dos que mais barbaramente pretendiam defender os direitos do indivíduo contra o poder do Estado ${ }^{12}$.

A cada necessidade, um novo serviço público; para cada problema, uma lei ou um código; cada inovação e cada progresso da técnica determinam uma regulamentação. E como as necessidades, os problemas, as invenções e o progresso material crescem num ritmo incessante, os serviços, as leis e as regulamentações se multiplicam ${ }^{13}$.

Nesse contexto, é possível falar do advento do Estado social que nos ensinamentos de Bonavides, quando o Estado, forçado pela pressão das massas, pelas reivindicações que a impaciência do povo faz ao poder político, confere, no Estado constitucional, os direitos ao trabalho, à previdência, à educação, e intervém na economia como distribuidor, dita salário, manipula a moeda, regula os preços, combate ao desemprego, protege os enfermos, dá ao trabalhador e ao burocrata a casa própria, controla as profissões, compra a produção, financia as exportações, concede crédito, institui comissões de abastecimento, atende necessidades de cunho individual, enfrenta crises econômicas, coloca na sociedade todas as classes na mais estreita dependência de seu poderio econômico, político e social, em síntese, estende sua influência a quase todos os domínios que antes pertenciam, em

${ }^{11}$ AZAMBUJA, Darcy. Teoria Geral do Estado. 4. ed. rev. ampl. e atual. São Paulo: Globo, 2008. p. 71.

12 AZAMBUJA, Darcy. Teoria Geral do Estado. 4. ed. rev. ampl. e atual. São Paulo: Globo, 2008. p. 71.

${ }^{13}$ AZAMBUJA, Darcy. Teoria Geral do Estado. 4. ed. rev. ampl. e atual. São Paulo: Globo, 2008. p. 71. 
DALALBA, Jennifer Leal Furtado Barreto; SOUILLJEE, Liege Giaretta; NISTLER, Regiane. A jurisdição no Estado Democrático de direito: uma breve análise do comportamento Ativista Judicial. Revista Eletrônica Direito e Política, Programa de Pós-Graduação Stricto Sensu em Ciência Jurídica da UNIVALI, Itajaí, v.13, n.1, $1^{0}$ quadrimestre de 2018. Disponível em: www.univali.br/direitoepolitica - ISSN 1980-7791

grande parte, à área de iniciativa individual. Nesse instante, o Estado pode, com justiça, receber a denominação de Estado social ${ }^{14}$.

Nesse modelo de Estado a visão tradicional dos direitos-liberdades, consagrados contra o poder, vem se sobrepor à concepção de direitos-créditos reconhecidos aos indivíduos, e que se traduzem por um poder de exigibilidade em relação ao Estado, uma vez que enquanto as liberdades clássicas impõem limitações para as ações do Estado, esses novos direitos pressupõem, ao revés, para a sua concretização, a mediação estatal; e seu caráter indefinidamente extensível motiva a ampliação ilimitada do Estado na vida da sociedade ${ }^{15}$.

Portanto, o Estado de bem-estar social surgiu para ser o garantidor dos "[...] tipos mínimos de renda, alimentação, saúde, habitação, educação, assegurados a todo cidadão não como caridade, mas como direito político ${ }^{16}$."

O direito, como visto, diante das mudanças estatais, não passa ileso, ao contrário, muda e tenta se adaptar conforme as novas demandas. Diante disso, é a fala de Ovidio Baptista da Silva, um dos doutrinadores que certamente mais ostenta propriedade ao tratar das dificuldades do exercício da jurisdição, ante as mais diversas demandas sociais:

O direito, antes de ser monopólio do Estado, era uma manifestação das leis de Deus, apenas conhecidas e reveladas pelos sacerdotes. O Estado não o produzia sob a forma de normas abstratas reguladoras da conduta humana. Nesse estágio de organização social e política, a atividade desenvolvida pelos pontífices, [...] não pode ser equiparada a função nitidamente jurisdicional. A verdadeira e autêntica jurisdição apenas surgiu a partir do momento em que o Estado assumiu uma posição de maior independência, desvinculando-se dos valores

\footnotetext{
${ }^{14}$ BONAVIDES, Paulo. Do estado liberal ao estado social. São Paulo: Malheiros, 2013. p. 60.

15 ARNAUD, André-Jean. Dicionário enciclopédico de Teoria e de Sociologia do Direito. Tradução de Patrice Charles. Rio de Janeiro: Renovar, 1999. p. 3320.

16 BOBBIO, Norberto. O futuro da democracia: uma defesa das regras do jogo. Tradução de Marco Aurélio Nogueira. Rio de Janeiro: Paz e Terra, 1996. p. 416.
} 
DALALBA, Jennifer Leal Furtado Barreto; SOUILLJEE, Liege Giaretta; NISTLER, Regiane. A jurisdição no Estado Democrático de direito: uma breve análise do comportamento Ativista Judicial. Revista Eletrônica Direito e Política, Programa de Pós-Graduação Stricto Sensu em Ciência Jurídica da UNIVALI, Itajaí, v.13, n.1, $1^{\circ}$ quadrimestre de 2018. Disponível em: www.univali.br/direitoepolitica - ISSN 1980-7791

estritamente religiosos e passando a exercer um poder mais acentuado de controle social ${ }^{17}$.

Contudo, atualmente, a tarefa de "dizer o direito" encontra limites na precariedade da jurisdição moderna, incapaz de responder às demandas contemporâneas produzidas por uma sociedade que avança tecnologicamente na velocidade da luz, permitindo o aumento da exploração econômica, caracterizada pela capacidade de produzir riscos sociais e pela incapacidade de oferecer-lhes respostas a partir dos parâmetros tradicionais ${ }^{18}$.

Diante disso, e sem delongas, considerando a brevidade da pesquisa, embora o tema mereça grande aprofundamento, é possível dizer ser muito claro que o Estado Social Democrático de Direito, bem como a nova forma de pensar o constitucionalismo nas últimas décadas, especialmente a partir do século XX alterou significativamente a atuação do Poder Judiciário. Durante um extenso lapso temporal, existia, na esfera das funções jurisdicionais, grande resistência à aplicação da Constituição, o que tornou a atividade do ato de decidir uma atividade mecânica, de pretensa reprodução legislativa. Esse contexto foi transformado no Brasil a partir da Constituição Federal de 1988, que potencializou o papel do Poder Judiciário, ao enfatizar o compromisso do Direito com a concretização do que estava previsto no texto da Carta Magna. Logo, é sabido que uma das marcas da mudança da concepção do Estado Social para o Estado Democrático de Direito é visto justamente pela transferência do polo de tensão do Poder Executivo para o Poder Judiciário, o que será estudado na seção seguir ${ }^{19}$.

Antes, porém, anote-se que nos tempos hodiernos parece existir uma preocupação com a aplicação da Constituição Federal, bem como com a

17 SILVA, Ovídio Araújo Baptista da; GOMES, Fábio Luiz. Teoria Geral do Processo Civil. São Paulo: Editora Revista dos Tribunais, 1997. p. 60.

18 SPENGLER, Fabiana Marion; BITENCOURT, Caroline M.; TURATTI, Luciana. Políticas públicas no tratamento dos conflitos. p. 14.

19 TASSINARI, Clarissa. A atuação do Judiciário em tempos de constitucionalismo contemporâneo. Rev. Fac. Dir. Sul de Minas, Pouso Alegre, v. 28, n. 2: 31-46, jul./dez. 2012. 
DALALBA, Jennifer Leal Furtado Barreto; SOUILLJEE, Liege Giaretta; NISTLER, Regiane. A jurisdição no Estado Democrático de direito: uma breve análise do comportamento Ativista Judicial. Revista Eletrônica Direito e Política, Programa de Pós-Graduação Stricto Sensu em Ciência Jurídica da UNIVALI, Itajaí, v.13, n.1, $1^{0}$ quadrimestre de 2018. Disponível em: www.univali.br/direitoepolitica - ISSN 1980-7791

entrega de uma prestação jurisdicional eficaz para a sociedade, a partir de decisões céleres e bem fundamentadas, uma vez que o Novo Código de Processo Civil, que entrou em vigor recentemente traz regras em um pano de fundo nitidamente constitucional, não apenas pela sua obrigatoriedade de seguir a Carta Magna, evidentemente, mas porque incorporou normas da Constituição Federal de 1988, como o destaque para o contraditório, a razoável duração do processo, a fundamentalidade das decisões, a publicidade dos atos e a imprescindibilidade da satisfação do julgamento ${ }^{20}$.

O novo Código de Processo Civil, então, funda o formalismo democrático rumo a uma cidadania participativa com objetivo de se obter uma resposta adequada em termos de conformação com os princípios constitucionais de justiça e os direitos fundamentais. A formulação de dizer o direito no âmbito do Estado Constitucional impõe a redução de subjetivismos, a correção de falhas, a redução de arbítrios e segue a trajetória da busca decisão-quadro, enfim, impõe conduzir comportamentos segundo os valores e os princípios constitucionais. O seu art. 10 fornece a direção, quando afirma: "O processo civil será ordenado, disciplinado e interpretado conforme os valores e as normas fundamentais estabelecidos na Constituição (...), observando-se as disposições deste Código ${ }^{21}$."

O guia maior do novo Código de Processo Civil é a formação de um sistema processual efetivamente democrático com base na coparticipação e cooperação dos indivíduos por meio da consolidação de que estes são titulares de direitos fundamentais e sociais, que assumem responsabilidades e possibilidades de interlocução ativa. São vários os seus dispositivos que consolidam esse nítido formalismo democrático, como por exemplo: (a) art. 10 - ampliação do debate contraditório; (b) arts. 926-927 - decisões servem

20 OLIVEIRA, Vallisney de Souza. A celeridade do Novo CPC. Disponível em: < http://politica.estadao.com.br/blogs/fausto-macedo/a-celeridade-no-novo-cpc/> Acesso em: 01 ago 2017.

21 ESTEVES, Alan da Silva; KRELL, Andreas. A função de julgar no novo código de processo civil: as interações entre o formalismo jurídico e o formalismo democrático. In: XXV Encontro Nacional do Conpedi - Brasília - DF. p. 01 - 22. 
DALALBA, Jennifer Leal Furtado Barreto; SOUILLJEE, Liege Giaretta; NISTLER, Regiane. A jurisdição no Estado Democrático de direito: uma breve análise do comportamento Ativista Judicial. Revista Eletrônica Direito e Política, Programa de Pós-Graduação Stricto Sensu em Ciência Jurídica da UNIVALI, Itajaí, v.13, n.1, $1^{\circ}$ quadrimestre de 2018. Disponível em: www.univali.br/direitoepolitica - ISSN 1980-7791

de substrato para um sistema que se vale dos precedentes como técnica decisória; (d) art. 357, § $2^{\circ}$ e $3^{\circ}$ - saneador negociado e compartilhado trata-se de fazer uma instrução melhor preparada22.

\section{ATIVISMO JUDICIAL E O ENFRAQUECIMENTO DA DEMOCRACIA}

A grande participação do Poder Judiciário na sociedade, em especial com o advento do Estado Democrático de Direito, como dito, evidenciou uma atividade ilimitada e duas principais expressões passaram a estar intimamente ligadas à atividade jurisdicional: a judicialização da política e o ativismo judicial, portanto, um dos problemas iniciais que se evidencia, e precisa ser superado, é a distinção entre eles ${ }^{23}$.

A judicialização da política tem sido percebida nos Estados Unidos, desde o famoso caso Marbury v. Madison, quando a atuação do Poder Judiciário, ao exercer o controle da constitucionalidade das leis, passou a apresentar uma atuação destacada na vida política e social daquele país. Contudo, foi a partir do século XX que a Corte Suprema revelou atuação mais clarividente em favor da concretização dos direitos de cunho individual, através do acolhimento de teses nessa linha, especialmente em fase de revisão judicial (o século $X X$, na história da Corte dos Estados Unidos foi marcado pela Era Lochner e pela lendária Corte Warren). Na verdade, a capacidade de os juízes e de os tribunais deste país interferirem no funcionamento das suas instituições é gigante e parece aumentar ainda mais com o passar dos anos ${ }^{24}$.

A judicialização da política pode ser compreendida como um fenômeno circunstancial, uma vez que decorre de um cenário de fortalecimento da

22 THEDORO JÚNIOR, Humberto. Novo CPC: fundamentos e sistematização. 2. ed. Rio de Janeiro, 2015, p. 20 ss.

23 TASSINARI, Clarissa. A atuação do Judiciário em tempos de constitucionalismo contemporâneo. Rev. Fac. Dir. Sul de Minas, Pouso Alegre, v. 28, n. 2: 31-46, jul./dez. 2012.

24 NUNES JUNIOR, Amandino Teixeira. A Judicialização da Política no contexto da Constituição de 1988. In: ARAÚJO, José Cordeiro de; PEREIRA JÚNIOR, José de Sena; PEREIRA, Lúcio Soares; RODRIGUES, Ricardo José Pereira (Orgs.). Ensaios sobre impactos da Constituição Federal de 1988 na sociedade brasileira: consultoria legislativa. Brasília: Centro de Documentação e Informação, 2008. p. 755. 
DALALBA, Jennifer Leal Furtado Barreto; SOUILLJEE, Liege Giaretta; NISTLER, Regiane. A jurisdição no Estado Democrático de direito: uma breve análise do comportamento Ativista Judicial. Revista Eletrônica Direito e Política, Programa de Pós-Graduação Stricto Sensu em Ciência Jurídica da UNIVALI, Itajaí, v.13, n.1, $1^{0}$ quadrimestre de 2018. Disponível em: www.univali.br/direitoepolitica - ISSN 1980-7791

jurisdição no pós-Segunda Guerra Mundial, e, simultaneamente, contigencial ${ }^{25}$, no sentido de que o Judiciário é chamado a interferir na inércia verificada em alguns dos Poderes do Estado, Legislativo e Executivo, especialmente este último, apresentando-se, dessa forma, como um resultado de uma conjuntura de cunho político-social ${ }^{26}$.

Ainda, este não é um fenômeno exclusivo ou particular do modelo do Estado norte-americano; ao revés, o constitucionalismo de ordem europeia, principalmente no segundo pós-guerra, também passou a ostentar característica ampliativa da atuação dos Tribunais Constitucionais, vindo de institutos como constitucionalização do direito, eficácia horizontal e vertical dos direitos fundamentais, ampliação bem como "reforço" desses direitos, uma vez que os Tribunais Constitucionais, em que pese existam antes disso, ganham nova versão após os regimes de cunho totalitário, sendo a grande "aposta" para a efetivação dos direitos fundamentais contidos nos textos constitucionais dos instrumentos de controle de constitucionalidade, ampliação dos conteúdos de natureza constitucional e ampliação dos direitos fundamentais, etc. ${ }^{27}$.

25 A expressão é de Clarissa Tassinari: "Primeiro, não há como negar o elo existente entre Direito e Política; Segundo, a inter-relação entre Direito e Política não autoriza a existência de ativismos judiciais; Terceiro, há um equívoco em considerar judicialização da política e ativismo judicial como se fosse o mesmo fenêmeno; E quarto, a judicialização da política é um "fenômeno contingencial", isto é, no sentido de que insurge na insuficiência dos demais Poderes, em determinado contexto social, independentemente da postula de juízes e tribunais, ao passo que o ativismo diz respeito a uma postura do judiciário para além dos limites institucionais." (p. 36-7). 6 Essa ideia de conflito entre decisões democráticas e os direitos fundamentais decorre da constatação de Mielke Silva ao analisar a tese da oposição entre o Estado de Direito e a Democracia: "[...] o papel do juiz é verificar se com aquela afetação do direito individual/grupo, ou (ou não?) o não cumprimento do dever que a constituição Ihes impõe. [...] Em que pese haver uma confluência no sentido da harmonia entre conflito entre decisões da maioria democrática e direitos fundamentais". SILVA, Jaqueline Mielke. A Democracia como Possibilidade de Produção de Sentido: o Papel do Poder Judiciário na Tutela de Direitos Fundamentais no Estado Social e Democrático de Direito. In: TRINDADE, Karam André; ESPÍNDOLA; Angela de Araújo da Silveira; BOFF, Salete Oro. (Org.). Direito, Democracia e Sustentabilidade: Anuário do Programa de Pós-Graduação Stricto Sensu em Direito da Faculdade Meridiconal. Passo Fundo: Imed, 2014. p. 323.

26 TASSINARI, Clarissa. A atuação do Judiciário em tempos de constitucionalismo contemporâneo. Rev. Fac. Dir. Sul de Minas, Pouso Alegre, v. 28, n. 2: 31-46, jul./dez. 2012.

27 GERVASONI, Tássia Aparecida. LEAL, Mônia Clarissa Hennig. Judicialização da política e ativismo judicial na perspectiva do Supremo Tribunal Federal. Curitiba: Multideia, 2013.p. 75. 
DALALBA, Jennifer Leal Furtado Barreto; SOUILLJEE, Liege Giaretta; NISTLER, Regiane. A jurisdição no Estado Democrático de direito: uma breve análise do comportamento Ativista Judicial. Revista Eletrônica Direito e Política, Programa de Pós-Graduação Stricto Sensu em Ciência Jurídica da UNIVALI, Itajaí, v.13, n.1, $1^{0}$ quadrimestre de 2018. Disponível em: www.univali.br/direitoepolitica - ISSN 1980-7791

É possível, portanto, identificar o fenômeno da judicialização da política como decorrente de alguns fatores: a) do dirigismo constitucional; b) do surgimento dos Tribunais Constitucionais na Europa; c) do aumento da litigiosidade; d) do crescimento do acesso à justiça; e) da crise da democracia. Nesse sentido, consegue-se identificar que a excessiva judicialização que assola as democracias modernas pode ser observada por um duplo viés: social e político. Ou seja, ela emerge tanto de um contexto social de exigência de direitos, bem como de um arranjo político de desídia na implementação desses mesmos direitos fora da jurisdição, questões que se imbricam mutuamente ${ }^{28}$.

Nesse sentido são as lições de Barroso para quem a judicialização da política significa que algumas questões de extensão repercussão política ou de cunho social estão sendo decididas por instituições do Poder Judiciário, e não pelas instituições políticas tradicionais: o Congresso Nacional e o Poder Executivo. Ainda, a judicialização envolve uma transferência de poder para juízes e tribunais, com mudanças relevantes na linguagem, na argumentação e no modo de participação da própria sociedade 2930.

28 TASSINARI, Clarissa. A atuação do Judiciário em tempos de constitucionalismo contemporâneo. Rev. Fac. Dir. Sul de Minas, Pouso Alegre, v. 28, n. 2: 31-46, jul./dez. 2012.

\footnotetext{
29 "A primeira grande causa da judicialização foi a redemocratização do país, que teve como ponto culminante a promulgação da Constituição de 1988. Nas últimas décadas, com a recuperação das garantias da magistratura, o Judiciário deixou de ser um departamento técnico-especializado e se transformou em um verdadeiro poder político, capaz de fazer valer a Constituição e as leis, inclusive em confronto com os outros Poderes. No Supremo Tribunal Federal, uma geração de novos Ministros já não deve seu título de investidura ao regime militar. Por outro lado, o ambiente democrático reavivou a cidadania, dando maior nível de informação e de consciência de direitos a amplos segmentos da população, que passaram a buscar a proteção de seus interesses perante juízes e tribunais. Nesse mesmo contexto, deuse a expansão institucional do Ministério Público, com aumento da relevância de sua atuação fora da área estritamente penal, bem como a presença crescente da Defensoria Pública em diferentes partes do Brasil. Em suma: a redemocratização fortaleceu e expandiu o Poder Judiciário, bem como aumentou a demanda por justiça na sociedade brasileira." BARROSO, Luís Roberto. Judicialização, ativismo judicial e legitimidade democrática. Disponível em: <http://www.oab.org.br/editora/revista/users/revista/1235066670174218181901.pdf> Acesso em: 07 de setembro de 2017.
}

30 BARROSO, Luís Roberto. Judicialização, ativismo judicial e legitimidade democrática. Disponível em: <http://www.oab.org.br/editora/revista/users/revista/1235066670174218181901.pdf> Acesso em: 01 jul. 2017. 
DALALBA, Jennifer Leal Furtado Barreto; SOUILLJEE, Liege Giaretta; NISTLER, Regiane. A jurisdição no Estado Democrático de direito: uma breve análise do comportamento Ativista Judicial. Revista Eletrônica Direito e Política, Programa de Pós-Graduação Stricto Sensu em Ciência Jurídica da UNIVALI, Itajaí, v.13, n.1, $1^{\circ}$ quadrimestre de 2018. Disponível em: www.univali.br/direitoepolitica - ISSN 1980-7791

Acerca das diferenças entre ativismo e judicialização da política, e iniciando o estudo sobre aquele, convém destacar que um juiz ou tribunal pratica ativismo quando decide a partir de argumentos de moral, de política, enfim, quando o direito acaba sendo substituído pelas convicções pessoais de cada magistrado, ou ainda, de um conjunto de magistrados. Enquanto isso, a judicialização da política é um fenômeno que surge por meio da relação entre os poderes do Estado, pensando aqui na tensão dos Poderes Executivo e Legislativo em direção da justiça constitucional ${ }^{31}$.

O termo ativismo judicial vem sendo utilizado no Brasil de uma maneira "tabula rasa", diz Streck. Isso porque nos Estados unidos a discussão acerca do governo dos juízes no que tange ao ativismo judicial soma mais de 200 anos. Aliás, não se pode olvidar, que o ativismo nos Estados Unidos foi feito às avessas, pelo menos num primeiro momento. Esse detalhe - que não seria o ativismo sempre algo positivo -, é verificado em uma postura da Corte estadunidense, em relação ao new deal que, aferrada às lições do liberalismo econômico, impedia, por inconstitucionalidade, as medidas intervencionistas estabelecidas pelo governo Roosevelt. As atitudes de natureza intervencionista em prol dos direitos humanos fundamentais acontecem em um cenário que dependia muito mais da ação individual de uma maioria do que do resultado de uma concepção propriamente ativista. O caso da Corte Warren, aqui já mencionado, a título de exemplo, foi para Streck, a

${ }^{31}$ STRECK, Lênio Luiz. Verdade e consenso. 4. ed. São Paulo: Saraiva, 2011. p. 123. 
DALALBA, Jennifer Leal Furtado Barreto; SOUILLJEE, Liege Giaretta; NISTLER, Regiane. A jurisdição no Estado Democrático de direito: uma breve análise do comportamento Ativista Judicial. Revista Eletrônica Direito e Política, Programa de Pós-Graduação Stricto Sensu em Ciência Jurídica da UNIVALI, Itajaí, v.13, n.1, $1^{0}$ quadrimestre de 2018. Disponível em: www.univali.br/direitoepolitica - ISSN 1980-7791

consequência da concepção pessoal de uma certa quantidade de juízes e não de um sentimento constitucional acerca desse problema 32 .

A título de adendo, nas lições de Dworkin ${ }^{34}$, a Corte Warren, em sua nítida posição ativista, tem como foco a preservação de direitos e garantias fundamentais, o que evidencia que a jurisdição constitucional "não coloca em xeque o regime democrático, mas o fortalece, ao contrário do que se verifica, por exemplo, na Corte Hughes, durante a era de transição", ensinam Morais e Trindade ${ }^{35}$.

Todavia, no Brasil, o temo toma "ares dramáticos", destaca Streck. Isso porque, para o autor, basta lembrar que ativismo judicial aparece como um princípio no anteprojeto do Código Brasileiro de Processo Coletivo (art. $2^{\circ}, \mathrm{i}$ ). Embora este projeto de lei não tenha sido ainda analisado pelo Congresso Nacional, a simples utilização do termo ativismo judicial como um "princípio

\footnotetext{
32 Um exemplo que bem retrata como essa discussão não tem sido feita satisfatoriamente no Brasil pode ser retirado da reclamação 4.335/AC (de consignar que a medida perdeu seu objeto com a edição da Lei n. 11.464/2007; todavia, o debate que sustentava a reclamação sempre volta à baila no campo jurídico brasileiro, e sua validade ilustrativa permanece inalterada). Com efeito, essa medida foi interposta pela Defensoria Pública do Estado do Acre no intuito de fazer valer entendimento do STF exarado em controle difuso de constitucionalidade (no caso, o problema da progressão de regime nos crimes hediondos). Como se sabe, a medida da reclamação é restrita para fazer cumprir decisões da corte que estejam revestidas de eficácia erga omnes e efeitos vinculantes, como ocorre no âmbito do controle concentrado. Nos casos de pronunciamento da corte em controle difuso, a Constituição, por força do art. 52, X, condiciona a suspensão da execução da lei declarada inconstitucional pelo STF à intervenção do Senado. Ocorre que parte dos Ministros entendeu que - em virtude de uma tendência à "concentração" do controle de constitucionalidade, visualizada nas mudanças operadas no texto da Constituição e nas várias leis infraconstitucionais - estaria ocorrendo uma mutação constitucional e que, por isso, no lugar em que a Constituição fala que "ao Senado cabe suspender a execução da lei", deveria ser lido "dar publicidade à lei declarada, no todo ou em parte, inconstitucional pelo STF." STRECK, Lênio Luiz. Verdade e Consenso. São Paulo: Saraiva, 2014. p. 61-62.
}

33 STRECK, Lênio Luiz. Verdade e Consenso. São Paulo: Saraiva, 2014. p. 61.

34 DWORKIN, Ronald. Levando os direitos a sério. São Paulo: Martins Fontes, 2002. p. 220-234.

35 TRINDADE, André Karam; MORAIS, Fausto Santos de. Ativismo judicial: a experiências norte-americana, alemã e brasileira. Revista da Faculdade de Direito - UFPR, Curitiba, n.47, p.29-64, 2011. 
DALALBA, Jennifer Leal Furtado Barreto; SOUILLJEE, Liege Giaretta; NISTLER, Regiane. A jurisdição no Estado Democrático de direito: uma breve análise do comportamento Ativista Judicial. Revista Eletrônica Direito e Política, Programa de Pós-Graduação Stricto Sensu em Ciência Jurídica da UNIVALI, Itajaí, v.13, n.1, $1^{0}$ quadrimestre de 2018. Disponível em: www.univali.br/direitoepolitica - ISSN 1980-7791

norteador" do processo coletivo brasileiro já demonstra o "estado de profundo impasse teórico que impera na doutrina ${ }^{36 " .}$

Sobre o ativismo judicial, parte-se do princípio de que ele consiste num profícuo instrumento de concreção da dignidade da pessoa humana, da cidadania, da justiça e da democracia. Por outro lado, existem temores conforme já aludido que a intervenção judicial em matérias politicamente controversas apresenta um "risco de juristocracia", ou um "governo de toga", ou seja, um aristocrático governo de juízes exercido sob o manto de uma atividade aparentemente técnica de interpretação de dispositivos jurídicos mediante conceitos da dogmática especificamente constitucional ${ }^{37}$.

O ativismo judicial exsurge no momento em que o magistrado não decide dentro dos limites trazidos pela Constituição Federal, atuando de maneira discricionária; questão que passa, portanto, pelo problema hermenêutico de interpretação da Constituição de 1988. São claras as posturas contrárias às decisões pelo Poder Judiciário onde há uma zona de penumbra na lei, mas é possível perceber a partir do elevado número de ações diretas propostas perante o Supremo Tribunal Federal, e, principalmente, pelas inúmeras decisões declaratórias de inconstitucionalidade de leis editadas pela União Federal e pelos Estados, comprovando que há uma deficiência de qualidade legislativa e, simultaneamente, parte do imprescindível equilíbrio entre os Poderes e compromete os direitos e principalmente as garantias fundamentais dos cidadãos ${ }^{38}$.

Através do ativismo judicial, permite-se uma interpretação constitucional que se liberte de alguns mitos ligados ao formalismo jurídico, à interpretação mecânica das normas jurídicas limitadas pelo positivismo jurídico normativista. Nesse contexto, altera-se o papel

36 STRECK, Lênio Luiz. Verdade e Consenso. São Paulo: Saraiva, 2014. p. 61.

37 TAFFAREL, Claridê Chitolina; DABULL, Matheus Silva. A efetivação dos direitos fundamentais sociais mediante o ativismo judicial. In: COSTA, Marli Marlene Moraes da (Org.) Direito \& Políticas Públicas VII. Curitiba: Multideia, 2012. P. 37.

38 LIMA, Wedner Costodio; LIMA, Wilian Costodio. Judcialização da política e ativismo judicial: o limite da interpretação da constituição e a relação entre direito e política na jurisdição constitucional. Anais do XII Seminário Nacional de Demandas Sociais e Políticas Públicas na Sociedade Contemporânea da Unisc, 2016. 
DALALBA, Jennifer Leal Furtado Barreto; SOUILLJEE, Liege Giaretta; NISTLER, Regiane. A jurisdição no Estado Democrático de direito: uma breve análise do comportamento Ativista Judicial. Revista Eletrônica Direito e Política, Programa de Pós-Graduação Stricto Sensu em Ciência Jurídica da UNIVALI, Itajaí, v.13, n.1, $1^{0}$ quadrimestre de 2018. Disponível em: www.univali.br/direitoepolitica - ISSN 1980-7791

do juiz, que se limitava a revelar uma solução que já se encontrava clara pela simples incidência da norma ao caso concreto e que agora, diante de casos complexos e na ausência de uma norma específica aplicável ao caso, precisa participar ativamente do processo de criação do direito, pois, uma vez que a resposta para o litígio não se encontra pronta na norma, o juiz terá que criar, argumentativamente, a solução para aquele caso específico que fora submetido à decisão do Poder Judiciário ${ }^{39}$.

Antes de continuar a explanação do tema é preciso dizer, ainda que a título de adendo, que a expressão positivismo é utilizada nessa pesquisa, sem prejuízo do estudo que merece o tema acerca das suas várias versões, especialmente conceitual/metodológica ${ }^{40}$, ideológica ${ }^{41}$, como a concepção do direito 42 que surge quando o "direito positivo" e o 'direito natural' não mais são considerados direito no mesmo sentido, mas o direito positivo passa a ser considerado como direito em sentido próprio. Por atuação do positivismo jurídico o direito natural é praticamente banido da categoria do direito: o

39 PIRES. Nara S.S. O ativismo judicial como forma de assegurar os direitos fundamentais face à crise da separação dos poderes. Conpedi 2014. Disponível em: http://www.publicadireito.com.br/artigos. Acesso em 07 de setembro de 2017.

40 "Como teoria, quer única e exclusivamente conhecer o seu próprio objeto. Procura responder a esta questão: o que é e como é o Direito? Mas já não lhe importa a questão de saber como deve ser o direito, ou como deve ele ser feito. É ciência jurídica e não política do Direito. Quando a si se designa como "pura" teoria do Direito, isto significa que ela se propõe garantir um conhecimento apenas dirigido ao Direito e excluir deste conhecimento tudo quanto não pertença ao seu objeto, tudo quanto não se possa, rigorosamente, determinar como Direito. Quer isto dizer que ela pretende libertar a ciência jurídica de todos os elementos que Ihe são estranhos. Esse é o seu princípio metodológico fundamental." Kelsen, Hans. Teoria Pura do Direito. 4. tiragem. Tradução de João Baptista Machado. São Paulo: Martins Fontes, 2014. p.01.

${ }^{41}$ É caracterizado em posturas que defendem a tese de que o direito positivo ostenta força obrigatória, ou seja, deve ser obedecido e aplicado por todos os magistrados, não importando quais escrúpulos morais estão envolvidos no "julgamento". Assim, é possível ter a título de conclusão que deve o direito ser aplicado pelo fato de ser direito, tão somente, ao passo que se torna indiferente nesse cenário o seu conteúdo, o que evidencia uma clara segregação entre direito e moral. STRECK, Lênio Luiz. Crítica Hermenêutica do Direito. $2^{a}$ ed. Porto Alegre: Livraria do Advogado, 2016. p. 20.

42 "O que é direito?" Pergunta que Hart faz e no intuito de respondê-la, cria uma teoria com dois traços marcantes e que convém mencionar: a) para ele ela é geral pois tem como objetivo definir qualquer ordenamento jurídico que seja vigente na sociedade contemporânea; e b) é descritiva, pois tem como objetivo tornar clara a estrutura do Direito e seu funcionamento, mas sem levar em conta a justificação moral das práticas jurídicas. HART, Herbert. O conceito de Direito. São Paulo: Martins Fontes, 2009. p. 19 e 240. 
DALALBA, Jennifer Leal Furtado Barreto; SOUILLJEE, Liege Giaretta; NISTLER, Regiane. A jurisdição no Estado Democrático de direito: uma breve análise do comportamento Ativista Judicial. Revista Eletrônica Direito e Política, Programa de Pós-Graduação Stricto Sensu em Ciência Jurídica da UNIVALI, Itajaí, v.13, n.1, $1^{0}$ quadrimestre de 2018. Disponível em: www.univali.br/direitoepolitica - ISSN 1980-7791

direito positivo é direito, o direito natural não é direito. A partir deste marco acrescentar o adjetivo "positivo" à expressão "direito" torna-se um pleonasmo ${ }^{43}$.

Retomando o tema, é preciso destacar que, por outro lado, o ativismo judicial é mantido exclusivamente pelo sistema jurídico, fazendo referência a um problema propriamente do Direito, ao passo que se constitui em um comportamento de natureza judicial criado por um ato de vontade, que em várias oportunidades, está revestido de um critério político como fundamento. Essa análise pode ser retirada da obra de Antoine Garapon, que aduz ser o ativismo uma questão de obediência a vontades, e de Christopher Wolfe, para quem a realidade ativista do Judiciário norte-americano, na menção dele, é verificado por decisões judiciais que não consistem em julgamentos, mas desejos ${ }^{44}$.

Ou seja, em síntese, é possível afirmar com veemência que o ativismo judicial é um problema criado pelo Direito, mas que sem dúvidas tem efeito reflexo em todas as demais esferas, sobre o qual a comunidade jurídica deve, primeiro, debruçar-se no interesse de questionar pelo seu sentido, para em seguida, apresentar uma resposta, considerando o pano de fundo do constitucionalismo democrático. $\mathrm{E}$, nessa pergunta, que deve buscar o caminho de como pode ser redigida e compreendida a manifestação judiciária, é possível encontrar posturas que evidenciam a indexação da decisão judicial a um ato de vontade do julgador ${ }^{45}$.

Em suma, pode-se afirmar que o ativismo judicial é um problema de teoria do direito. Mais precisamente, de teoria da interpretação, na medida em que sua análise e definição dependem do modo como se olha para o problema da interpretação no Direito. Vale dizer: é a

43 BOBBIO, Norberto. O positivismo jurídico: lições de filosofia do direito. São Paulo: Ícone, 1996, p. 26.

44 TASSINARI, Clarissa. A atuação do Judiciário em tempos de constitucionalismo contemporâneo. Rev. Fac. Dir. Sul de Minas, Pouso Alegre, v. 28, n. 2: 31-46, jul./dez. 2012.

45 TASSINARI, Clarissa. A atuação do Judiciário em tempos de constitucionalismo contemporâneo. Rev. Fac. Dir. Sul de Minas, Pouso Alegre, v. 28, n. 2: 31-46, jul./dez. 2012. 
DALALBA, Jennifer Leal Furtado Barreto; SOUILLJEE, Liege Giaretta; NISTLER, Regiane. A jurisdição no Estado Democrático de direito: uma breve análise do comportamento Ativista Judicial. Revista Eletrônica Direito e Política, Programa de Pós-Graduação Stricto Sensu em Ciência Jurídica da UNIVALI, Itajaí, v.13, n.1, $1^{0}$ quadrimestre de 2018. Disponível em: www.univali.br/direitoepolitica - ISSN 1980-7791

interpretação um ato de vontade do intérprete ou o resultado de um projeto compreensivo no interior do qual se operam constantes suspensões de pré-juízos que constitui a perseguição do melhor (ou correto) sentido para a interpretação ${ }^{46}$ ?

No intuito de responder a respectiva pergunta, e citando as lições de Clarissa Tassinari, que utiliza da doutrina de Roberto Gagarella ${ }^{47}$, jurista argentino, a última opção, qual seja, "de que [o ativismo judicial] é o resultado de um projeto compreensivo no interior do qual se operam constantes suspensões de pré-juízos que constitui a perseguição do melhor (ou correto) sentido para a interpretação?" , parece ter resposta positiva e ser aderida pelos autores, à medida que o problema acerca da atuação do Poder Judiciário está em torno do fato de que as Cortes possuem a última palavra, e não da caracterização de uma dependência política dos julgadores, embora seja necessário considerar essa questão relevante também ${ }^{48}$.

Na verdade, a crítica segue na crença de que o Poder Judiciário é a instituição que ostenta a autoridade interpretativa de dizer o que a Constituição do país significa. Ou seja, há uma fragilidade da democracia quando se percebe esse fato, que claramente enfraquece a própria atuação dos indivíduos e de outras instituições. Ao fim e ao cabo, resta destacar que "se há problemas nas relações entre os Poderes, estes não podem ser resolvidos à margem do pressuposto democrático ${ }^{49 \prime \prime}$.

46 TASSINARI, Clarissa. A atuação do Judiciário em tempos de constitucionalismo contemporâneo. Rev. Fac. Dir. Sul de Minas, Pouso Alegre, v. 28, n. 2: 31-46, jul./dez. 2012.

47 GARGARELLA, Roberto. In search of a democratic justice: what courts should not do. In: GLOPPEN, Siri; GARGARELLA, Roberto; SAKAAR, Elin (Editors). Democratization and the judiciary: the accountability functions of courts in new democracies. London/ Portland: Frank Cass, 2004.

48 TASSINARI, Clarissa. A atuação do Judiciário em tempos de constitucionalismo contemporâneo. Rev. Fac. Dir. Sul de Minas, Pouso Alegre, v. 28, n. 2: 31-46, jul./dez. 2012.

49 TASSINARI, Clarissa. A atuação do Judiciário em tempos de constitucionalismo contemporâneo. Rev. Fac. Dir. Sul de Minas, Pouso Alegre, v. 28, n. 2: 31-46, jul./dez. 2012. 
DALALBA, Jennifer Leal Furtado Barreto; SOUILLJEE, Liege Giaretta; NISTLER, Regiane. A jurisdição no Estado Democrático de direito: uma breve análise do comportamento Ativista Judicial. Revista Eletrônica Direito e Política, Programa de Pós-Graduação Stricto Sensu em Ciência Jurídica da UNIVALI, Itajaí, v.13, n.1, $1^{0}$ quadrimestre de 2018. Disponível em: www.univali.br/direitoepolitica - ISSN 1980-7791

\section{CONSIDERAÇÕES FINAIS}

O texto, ainda que breve para um tema tão relevante tratou das mudanças das formas de Estado, destacando a velocidade com que isso acontece e a inevitabilidade desse movimento, o que é elucidado pelo próprio curso da história, com o Estado absoluto, liberal e social, e suas características indeléveis, como soberania, território, elemento humano e jurisdição, que em cada formato estatal, aparecem ao seu modo.

O ponto crucial reside no fato de a organização do Estado, especialmente de ordem democrática, se verifica na separação de poderes, bem como o respeito a essa divisão de competências, sendo que, em se tratando do Estado brasileiro, não por acaso, a Carta Magna garantiu autonomia e igualdade a cada um dos poderes, assim como aos entes políticos, nos termos da Constituição.

Contudo, o que não é segredo, ao revés, é de caráter notório e muito tem chamado a atenção, é o fato da enorme quantidade de demandas judiciais versarem sobre a efetivação de direitos básicos, aqueles direitos mínimos destacados no Estado Social Democrático de Direito como: alimentação, saúde, educação, entre outros, acerca dos quais se espera atuação dos Poderes Legislativo e Executivo, especialmente este último, sendo o Poder Judiciário nesses casos, uma alternativa subsidiária.

Mas o problema não reside somente nesse fenômeno, intitulado de judicialização da política, como exposto. O ponto nevrálgico é que o Poder Judiciário tem excedido seus próprios limites ao julgar casos dessa natureza, à medida que tem cabido a ele decidir o que a Constituição do país significa, enfraquecendo evidentemente a democracia, à medida que com esse ato fragiliza as outras instituições e os próprios indivíduos, embora pareça decidir ao seu favor, o que não se pode admitir. 
DALALBA, Jennifer Leal Furtado Barreto; SOUILLJEE, Liege Giaretta; NISTLER, Regiane. A jurisdição no Estado Democrático de direito: uma breve análise do comportamento Ativista Judicial. Revista Eletrônica Direito e Política, Programa de Pós-Graduação Stricto Sensu em Ciência Jurídica da UNIVALI, Itajaí, v.13, n.1, $1^{\circ}$ quadrimestre de 2018. Disponível em: www.univali.br/direitoepolitica - ISSN 1980-7791

\section{REFERÊNCIAS DAS FONTES CITADAS}

ARNAUD, André-Jean. Dicionário enciclopédico de Teoria e de Sociologia do Direito. Tradução de Patrice Charles. Rio de Janeiro: Renovar, 1999.

AZAMBUJA, Darcy. Teoria Geral do Estado. 4. ed. rev. ampl. e atual. São Paulo: Globo, 2008.

BARROSO, Luís Roberto. Judicialização, ativismo judicial e legitimidade democrática. Disponível em: <http://www.oab.org.br/editora/revista/users/revista/12350666701742181 81901.pdf> Acesso em: 07 de setembro de 2017.

BOBBIO, Norberto. O futuro da democracia: uma defesa das regras do jogo. Tradução de Marco Aurélio Nogueira. Rio de Janeiro: Paz e Terra, 1996.

BOBBIO, Norberto. O positivismo jurídico: lições de filosofia do direito. São Paulo: İ́cone, 1996.

BONAVIDES, Paulo. Do estado liberal ao estado social. São Paulo: Malheiros, 2013.

CICCO, Cláudio de; GONZAGA, Álvaro de Azevedo. Teoria Geral do Estado e ciência política. São Paulo: Editora Revista dos Tribunais, 2008.

DALLARI, Dalmo de Abreu. Elementos de Teoria Geral do Estado. São Paulo: SARAIVA, 2015.

DWORKIN, Ronald. Levando os direitos a sério. São Paulo: Martins Fontes, 2002.

ESTEVES, Alan da Silva; KRELL, Andreas. A função de julgar no novo código de processo civil: as interações entre o formalismo jurídico e o formalismo democrático. In: XXV Encontro Nacional do Conpedi Brasília - DF.

GARGARELLA, Roberto. In search of a democratic justice: what courts should not do. In: GLOPPEN, Siri; GARGARELLA, Roberto; SAKAAR, Elin (Editors). Democratization and the judiciary: the accountability functions of courts in new democracies. London/ Portland: Frank Cass, 2004.

GERVASONI, Tássia Aparecida. LEAL, Mônia Clarissa Hennig. Judicialização da política e ativismo judicial na perspectiva do Supremo Tribunal Federal. Curitiba: Multideia, 2013.

HART, Herbert. O conceito de Direito. São Paulo: Martins Fontes, 2009.

HELLER. Teoria do Estado. Tradução de Lycurgo Gomes da Motta. São Paulo: Mestre Jou, 1968. Título original: Staatslehre. 
DALALBA, Jennifer Leal Furtado Barreto; SOUILLJEE, Liege Giaretta; NISTLER, Regiane. A jurisdição no Estado Democrático de direito: uma breve análise do comportamento Ativista Judicial. Revista Eletrônica Direito e Política, Programa de Pós-Graduação Stricto Sensu em Ciência Jurídica da UNIVALI, Itajaí, v.13, n.1, $1^{\circ}$ quadrimestre de 2018. Disponível em: www.univali.br/direitoepolitica - ISSN 1980-7791

HOBBES, Thomas. Leviatã, ou a matéria, forma e poder de um estado eclesiástico e civil. Tradução de Rosina D'Angina. São Paulo: Ícone, 2000. Título original: Leviathan, or Matter, Form and Power of a Commenweath Ecclesiastical and Civil.

LIMA, Wedner Costodio; LIMA, Wilian Costodio. Judicialização da política e ativismo judicial: o limite da interpretação da constituição e a relação entre direito e política na jurisdição constitucional. Anais do XII Seminário Nacional de Demandas Sociais e Políticas Públicas na Sociedade Contemporânea da Unisc, 2016.

MIRANDA, Jorge. Teoria do Estado e da Constituição. Rio de Janeiro: Forense, 2011.

NUNES JUNIOR, Amandino Teixeira. A Judicialização da Política no contexto da Constituição de 1988. In: ARAÚJO, José Cordeiro de; PEREIRA JÚNIOR, José de Sena; PEREIRA, Lúcio Soares; RODRIGUES, Ricardo José Pereira (Orgs.). Ensaios sobre impactos da Constituição Federal de 1988 na sociedade brasileira: consultoria legislativa. Brasília: Centro de Documentação e Informação, 2008.

OLIVEIRA, Vallisney de Souza. A celeridade do Novo CPC. Disponível em: $<\quad$ http://politica.estadao.com.br/blogs/fausto-macedo/a-celeridade-nonovo-cpc/> Acesso em: 01 ago 2017.

PASOLD, Cesar Luiz. Função Social do Estado Contemporâneo. Santa Catarina: Ladesc, 1984.

PIRES. Nara S.S. O ativismo judicial como forma de assegurar os direitos fundamentais face à crise da separação dos poderes. Conpedi 2014. Disponível em: http://www.publicadireito.com.br/artigos. Acesso em 07 de setembro de 2017.

SANTI, Romano. Princípios de direito constitucional geral. São Paulo: ed. Revista dos Tribunais, 1977.

SPENGLER, Fabiana Marion; BITENCOURT, Caroline M.; TURATTI, Luciana. Políticas públicas no tratamento dos conflitos.

SILVA, Jaqueline Mielke. A Democracia como Possibilidade de Produção de Sentido: o Papel do Poder Judiciário na Tutela de Direitos Fundamentais no Estado Social e Democrático de Direito. In: TRINDADE, Karam André; ESPÍNDOLA; Angela de Araújo da Silveira; BOFF, Salete Oro. (Org.). Direito, Democracia e Sustentabilidade: Anuário do Programa de Pós-Graduação Stricto Sensu em Direito da Faculdade Meridiconal. Passo Fundo: Imed, 2014.

SILVA, Ovídio Araújo Baptista da; GOMES, Fábio Luiz. Teoria Geral do Processo Civil. São Paulo: Editora Revista dos Tribunais, 1997. p. 60. 
DALALBA, Jennifer Leal Furtado Barreto; SOUILLJEE, Liege Giaretta; NISTLER, Regiane. A jurisdição no Estado Democrático de direito: uma breve análise do comportamento Ativista Judicial. Revista Eletrônica Direito e Política, Programa de Pós-Graduação Stricto Sensu em Ciência Jurídica da UNIVALI, Itajaí, v.13, n.1, $1^{0}$ quadrimestre de 2018. Disponível em: www.univali.br/direitoepolitica - ISSN 1980-7791

STRECK, Lênio Luiz. Crítica Hermenêutica do Direito. $2^{a}$ ed. Porto Alegre: Livraria do Advogado, 2016.

STRECK, Lênio Luiz. Verdade e consenso. 4. ed. São Paulo: Saraiva, 2011.

TAFFAREL, Claridê Chitolina; DABULL, Matheus Silva. A efetivação dos direitos fundamentais sociais mediante o ativismo judicial. In: COSTA, Marli Marlene Moraes da (Org.) Direito \& Políticas Públicas VII. Curitiba: Multideia, 2012.

TASSINARI, Clarissa. A atuação do Judiciário em tempos de constitucionalismo contemporâneo. Rev. Fac. Dir. Sul de Minas, Pouso Alegre, v. 28, n. 2: 31-46, jul./dez. 2012.

THEDORO JÚNIOR, Humberto. Novo CPC: fundamentos e sistematização. 2. ed. Rio de Janeiro, 2015.

TRINDADE, André Karam; MORAIS, Fausto Santos de. Ativismo judicial: a experiências norte-americana, alemã e brasileira. Revista da Faculdade de Direito - UFPR, Curitiba, n.47, p.29-64, 2011.

Submetido em: 19/02/2018

Aprovado em: 13/03/2018 